\title{
Scientificity and Reasonability of Hospital Construction
}

\author{
Jinguo Wang ${ }^{1, a}$ and corresponding author: Na Wang ${ }^{2, b,{ }^{*}}$ \\ ${ }^{1}$ Department of Urology, The First Hospital of Jilin University, Changchun, China \\ ${ }^{2}$ Department of Anesthesiology, The First Hospital of Jilin University, Changchun, China \\ awangjinguolily@163.com, bwangna080613@163.com
}

\begin{abstract}
Keywords: Design, Hospital, Construction.
Abstract. Diseases, patients and society are closely integrated together. The role of evolution of infectious disease is associated with the design of hospital building, because of the extension characteristics of the diseases from an individual to the public in and outside the hospital building. This paper analyzes the reform on hospital architecture from a sociological point of view. Combining with the design theory and practical experience, it has presented a social picture of a comprehensive modern hospital building. The problems which exist in the development of hospital are analyzed. It is one of the most serious problems that the preliminary planning and evaluation is weak or missing.
\end{abstract}

\section{Introduction}

Every medical student makes the solemn oath of the Hippocratic oaths, when he enters the medical university. The oath is seen as a doctor for the patient to vow to take the social responsibility. It has been in use for over 2000 years, to shape the professional spirit. It is of far-reaching significance. The moral value system of modern hospital culture construction provides a profound cultural soil, which pays attention to moral and personality cultivation. It is always one of the most important content in the construction of hospital culture. [1]

An architect should pay close attention to hardware, which mainly refer to the material status in hospitals, including medical equipment, hospital building, hospital environment, medical technology and hospital benefits. Designers have used a lot of green design concepts to target the creation of a sustainable, organic medical architecture. [2]

The construction of hospital campus will promote the development of urban community and connect directly with urban transportation and public facilities planning. As one of the largest public buildings in the region, the medical center has conveyed its urbanized expression to people with its open park planning, outdoor square and garden space. [3]

\section{Scientificity and Reasonability.}

Humanistic Care. In terms of cultural expression, there is a general lack of individuality, cultural expression and sufficient humanistic care in Chinese hospital buildings. At present, in the field of hospital architecture design, designers focused on the most humane, intelligent, green hospital and new technology, new equipment, the system research of hospital architectural culture expression is little. [4] However, the management of the hospital tends to focus on functional requirements and a little attention is paid to the hospital culture in architecture.

The most important function of architecture is to meet certain functional requirements, but it is also a cultural symbol. As a special type of architecture, hospital architecture is an important symbol of the progress of a country and a region. Hospital culture has a broad and narrow sense. General hospital culture refers to the hospital in the long-term medical practice, the specific the sum total of material wealth and spiritual wealth created, containing soft hard hospital culture and hospital culture, the two aspects of both belong to the dialectical relationship, hospital culture is a cultural formation and development of soft foundation, such as hospital building soft culture, in turn, ACTS on the hard culture. [5]

Comprehensive Design. In addition to the need for modern medical technologies and medical models, a good environment is also essential. Modern hospitals should emphasize natural and harmless green 
medical environment. The rational overall layout of the scheme has formed the green landscape, the entrance plaza, the atrium of the medical street, the landscape courtyard, the roof garden, etc. [6] Hospital buildings have many special requirements.

The architect should not only meet the complex medical function requirements when designing hospital buildings. It also emphasizes the harmonious coexistence of architecture and environment, focusing on energy conservation and consumption, and realizing the flexible adaptability of architectural design to meet the sustainable development needs of buildings. [7]

Functional partitions and streamlining organizations are the focus. With the improvement of people's quality of life and spiritual needs. The design of hospital architecture not only needs to solve the problem of the functional division. It should be more efficient and convenient and people-oriented. [8] Efficient and orderly operation. The overall planning should consider the efficient and orderly operation of the hospital with reasonable and effective traffic streamline organization and function configuration. It is the key point of hospital architecture design to ensure the convenient traffic streamline and improve the efficiency of diagnosis and treatment. [9] Exit the entrance to the underground garage near the outpatient department, the emergency department and the hospital. It is also important to solve the problem of parking difficulty, and ensure the good order of people in the courtyard. [10]

Traditional hospital is designed as the standard of public facilities, and the design of the building main body is the pursuit of the three-dimensional effect, exterior case the use of glass curtain wall or the window more, but the use of glass walls while the three-dimensional and architectural design of convenient effect is better, the strong light for bedridden patients will have great negative impact, dazzle light phenomenon could occur. [11]

Pleasant indoor environment at the same time can also be implemented by means of the green plant, which can adjust the oxygen content in air, for patients and medical workers have the positive significance. The role of adjuvant therapy also can't be ignored. [12] Therefore, in the whole medical environment space should ensure the reasonable arrangement of indoor environment.

\section{Culture Expression of the Hospital Construction}

The hospital landscape has become a unique cultural carrier of the hospital spirit and has the function of cultural inheritance guide. The medical culture adopts the landscape approach and the science teaching approach in the hospital. As the current our country economy the accelerating pace of social development and the ageing, e problem increasingly prominent, and the spread of disease pattern extensions, means that our country hospital building design will become an important issue in the field of architectural design. [13] At the same time, Chinese building modern hospital needs to be expanded or rebuilt, under the background of modern hospital should not only meet the traditional health care function, but also should meet the comprehensive needs of hospital service principals.

At present, the Chinese modern medical often architectural design mainly based on the principle of people-oriented, excellent design, the purpose is to be able to help patients get treatment in a better environment, achieve physical rehabilitation, at the same time also can improve staff work efficiency and work enthusiasm. [14]

From the day of her birth, a hospital has accumulated its own culture, accumulated its own traditions and humanistic medicine spirit, and also inherits the spirit of traditional Chinese humanistic medicine. Hospital culture construction is not so much construction as excavation, inheritance and development of culture, or the existing cultural induction, summary, concise, and improve the potential cultural influence of the cultural influence of development become a reality. [15]

As a result, the hospital culture construction should be combined with traditional Chinese medicine and hospital's own medical humanities characteristics, the humanities spirit and tradition, guide the whole society especially in medical staff and the vast majority of patients and their families advocate medicine, respect for life, respect for doctors, health care, make the medical staff are proud to work in the medical. 


\section{Conclusions}

Hospital culture can and should be displayed in all aspects of hospital architecture. At present, the level of Chinese hospital architecture in cultural expression is still monotonous, repetitive and imitative, and there are many related topics to be further studied in the future. The author thought that doing good building types of cultural expression is a quick way to learn, study of religious architecture cultural expression, can provide can reference for hospital building culture expression method.

It is hoped that more and more people can pay attention to the cultural expression of hospital buildings, and actively explore and practice, so as to promote the development of hospitals in China to a higher level.

\section{References}

[1] Kwang Ree Cho, Ho Young Hwang, Jun-Sung Kim, Dong Seop Jeong, Ki-Bong Kim. Comparison of Right Internal Thoracic Artery and Right Gastroepiploic Artery Y Grafts Anastomosed to the Left Internal Thoracic Artery. The Annals of Thoracic Surgery. 2010

[2] Loong Chun-Keung, Wei Jie, Tang Chuanxiang. The future of neutron scattering in China: Meeting increasing demand with new facilities?. Journal of Physics: Conference Series; International Conference on Neutron Scattering 2009. 2010

[3] Dean A O. Sharon Hospital, Sharon, Connecticut. Architectural Record. 1997

[4] Lubin B S, Powell T. Pressure sores and specialty beds: cost containment and ensurance of quality care. Journal of ET nursing: official publication, International Association for Enterostomal Therapy. 1991

[5] CABE. Creating Successful Masterplans: A Guide for Client. http://www.cabe.org.uk.masterplans. 2003

[6] Ken Baynes, Brian Langslow, Courtenay C. Wade. Evaluating New Hospital Buildings. 1969

[7] Xiaoli Tian. Michelle Renshaw, Accommodating the Chinese: the American Hospital in China, 1880-1920. Medical History. 2009

[8] Ulrich R S. View through a window may influence recovery from surgery. Science. 1984

[9] Solomon Nancy B. Environmentally-friendly building strategies slowly make their way into medical facilities. Architectural Record. 2004

[10] Berry Leonard L, Parker Derek, Coile Russell C. The business case for better buildings. Frontiers of health services management. 2004

[11] Laska Eugene M, Meisner Morris, Siegel Carole, Wanderling Joseph. Statistical determination of cost-effectiveness frontier based on net health benefits. Journal of Health Economics. 2002

[12] Robinson J C. Decline in hospital utilization and cost inflation under managed care in California. JAMA: the journal of the American Medical Association. 1996

[13] Sean Stanwick. Site Lines - Thunder Bay Regional Health Sciences Centre. Architectural design: A.D. 2004

[14] Kathleen R. Farrar. Medicine The Hospital. A Social and Architectural History. The British Journal for the History of Science 1977

[15] M Younis, J Rice, J Barkoulas. An empirical investigation of hospital profitability in the post-PPS era. Journal of Health Care Finance. 2001 